\title{
Genetic diversity of South African dairy goats for genetic management
}

\section{and improvement}

\author{
Lydia Bosman, Esté van Marle-Köster*, Carina Visser
}

Department of Animal and Wildlife Sciences, University of Pretoria, Private Bag X 20, Hatfield 0028, South Africa

Lydia Bosman: $\underline{\text { u25014375@tuks.co.za }}$

Esté van Marle-Köster: evm.koster@up.ac.za

Carina Visser: carina.visser@up.ac.za

Corresponding author:

Este van Marle-Köster:

E-mail: evm.koster@up.ac.za

Department of Animal and Wildlife Sciences, University of Pretoria, Private Bag X 20, Hatfield 0028, South Africa

Tel: +27124203612

Fax: +27124203290

\section{Highlights}

- 240 dairy goats from three breeds were genotyped using 25 microsatellite markers.

- Moderate to high levels of genetic diversity was observed in all breeds.

- Limited inbreeding was indicated by $F_{\mathrm{IS}}$ values.

- Populations clustered into three breeds and a crossbred population cluster.

- Uncontrolled cross breeding should be avoided to maintain breed integrity.

\begin{abstract}
The dairy goat industry is a small, but important role player in the South African agricultural sector. The limited number of animals representing the three main breeds (Saanen, British Alpine and Toggenburg) has raised concerns over the genetic diversity of these animals and the impact on their genetic management. In this study 240 dairy goats representing three breeds were genotyped with 25 microsatellite markers. Sufficient levels of genetic diversity were observed in all the breeds, with
\end{abstract}


observed heterozygosity values exceeding $60 \%$. A slight population differentiation was indicated by the low $\mathrm{F}_{\mathrm{ST}}$ values across and within the populations. This was confirmed by the AMOVA analyses with most of the variation shown within populations (91.7\%). Negative $\mathrm{F}_{\text {IS }}$ values in the three breeds indicated limited inbreeding. Population structure analyses revealed six distinct groups, with the Saanen population clustering into three sub-groups. The Toggenburg and British Alpine breeds formed their own separate cluster, with a last cluster formed by animals from all three pure-bred populations, indicating high levels of admixture. These results caution farmers against uncontrolled crossbreeding practices and recommend routine evaluation of genetic diversity.

Keywords: British Alpine, Genetic variation, Microsatellite markers, Population structure, Saanen, Toggenburg

*Corresponding author: Tel +27 12420 3612; Fax +27 12420 3290; E-mail: evm.koster@up.ac.za

\section{Introduction}

Dairy goats were introduced to South Africa at the turn of the $20^{\text {th }}$ century, originating primarily from Switzerland and the United Kingdom. Originally four breeds were officially recognised in South Africa, namely the Saanen, Toggenburg, British Alpine and an Anglo-Nubian Swiss composite (Muller, 2005). Current dairy goat production systems include purebred Saanen, Toggenburg and British Alpine goats as well as crosses between these breeds.

The total goat population in South Africa is estimated at 6.2 million animals of which $63 \%$ are unimproved types (FAO, 2012). The dairy goat sector is however small with only approximately 4000 goats (Directorate: Animal Production, 2007). Despite this relatively small population size, a niche market is served with production of fresh milk and specialty cheeses (Directorate: Animal Production, 2007). Marketing of these products occur mostly in an informal way, such as by selling directly to consumers via on-farm sales, or at fresh food, organic or farmer's markets. Limited quantities of local goat's milk products are sold through retailers and supermarket chains, therefore no official milk production figures are available, but unofficial estimates gauge South African goat milk production around 1.4 million tonnes per annum (Directorate: Animal Production, 2007). 
The continuous supply of goat milk is hampered by the seasonality of production seen in the commercial herds, where around $82 \%$ of the does kid in the spring (Muller, 2005), resulting in a couple of months in a year when no fresh goats' milk is produced. The total volume of milk produced is insufficient to warrant investment in large scale freezing facilities to ensure year-round supply (Directorate: Animal Production, 2007).

The dairy goat population in South Africa originates from a small number of foundation animals that were imported from Germany, Switzerland, Italy, France and the United Kingdom during the early 1900's (Muller, 2005). Despite limited additional imports over the past few decades, the South African population has been isolated from the rest of the world's goat production centres largely due to logistical difficulties. There is a growing interest in keeping dairy goats and concerned breeders are questioning whether there is sufficient genetic variation within the population to support the growing industry. Microsatellite markers have been widely used to assess genetic diversity in livestock species, including goats (Saitbekova et al., 1999). In this study a panel of microsatellite markers was used to assess the genetic diversity of the South African commercial dairy goat population to guide decision making for genetic management and improvement.

\section{Materials and methods}

\subsection{Sample collection and DNA extraction}

A total of 240 dairy goats were sampled for the study with consent of the individual farmers and breeders. Ethical approval (EC088-12) for the study was obtained from the University of Pretoria Animal Use and Care Committee in the Faculty of Natural and Agricultural Sciences. Blood was collected from 240 dairy goats (130 Saanen, 51 Toggenburg and 59 British Alpine) from 13 dairy goat farms representing seven provinces in South Africa (Figure 1). Six of these farms specialized in only one of the breeds (5 in Saanen and 1 in Toggenburg), while the remainder had two or more of these breeds in their herds. Both registered and grade animals were sampled from these herds, and pedigree records were used to ensure unrelated sampling. In instances where on-farm records were unavailable, random sampling based on differences in age and production status were performed to prevent sampling related animals. 


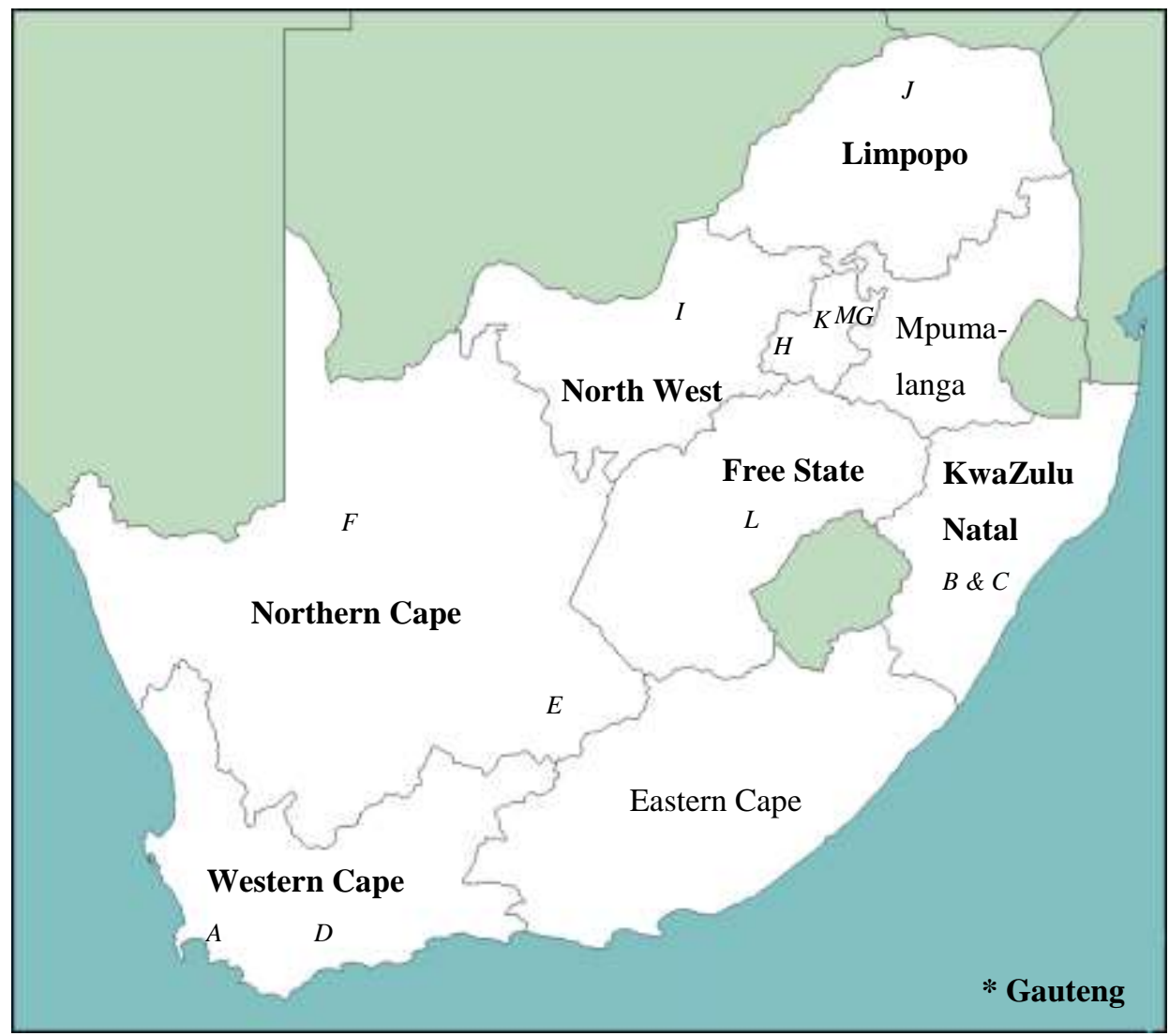

Fig. 1 Sampling locations with the sampled provinces printed in bold, the closest town shown in italics $(A$ : Paarl; $B \& C$ : Nottingham Road; $D$ : Montague; $E$ : De Aar; F: Middelpos; $G$ : Bronkhorstspruit; $H$ : Hekpoort; $I$ Delareyville; J: Louis Trichardt; K: Pretoria; $L$ : Brandfort; $M$ : Rayton)

$5 \mathrm{ml}$ blood was collected from the jugular vein of mature goats using EDTA tubes. The blood samples were transferred into screw-top tubes, which was duplicated for each sample, and stored at $40^{\circ} \mathrm{C}$ until DNA extraction. DNA was extracted using a Qiagen DNeasy ${ }^{\circledR}$ Blood and Tissue kit (Qiagen, Hilden, Germany), according to the standard protocol prescribed by the manufacturer in the Animal Breeding and Genetics Laboratory of the Department of Animal and Wildlife Sciences at the University of Pretoria.

\subsection{Genotyping and statistical analysis}

Twenty-five microsatellites were used for this study, consisting of 16 markers from the FAO/ISAG panel recommended for diversity studies in goats (FAO, 2011). Three additional markers 
from studies by Glowatzki-Mullis et al. (2008), Barrera-Saldaña et al. (2010) and Bruno-de-Sousa et al. (2011), as well as six markers from Visser et al. (2011) were respectively added based on the polymorphic nature reported in these studies.

The microsatellites were fluorescently labelled, and PCR amplification was carried out using a GeneAmp® PCR System 9700 thermocycler (Applied Biosystems, Foster City, USA). Successful amplicons were genotyped using an ABI PRISM® ${ }^{\circledR}$ 3500XL DNA Genetic Analyser (Applied Biosystems, Foster City, USA) at the FABI (Forestry and Agricultural Biotechnology Institute) sequencing laboratory of the University of Pretoria. Raw genotyping results were processed with the GeneMarker ${ }^{\mathrm{TM}}$ software (www.softgenetics.com/GeneMarker.html) to determine the fragment sizes for each locus for further analysis. Excel Microsatellite Toolkit (Park, 2001) was used to perform quality control and to determine polymorphic information content (PIC) values. Data conversion for use in other statistical software were performed with CONVERT 1.31 (Glaubitz, 2004) software. CONVERT and MSTookit (Park, 2001) were used to calculate allelic frequencies, mean number of alleles, observed and expected heterozygosity in the different populations. Private alleles within the populations were also identified using this software.

FSTAT version 2.9.3.2 (Goudet, 2001) was used to calculate Wright's $F$-statistics $\left(\mathrm{F}_{\mathrm{ST}}, \mathrm{F}_{\mathrm{IT}}\right.$, $\mathrm{F}_{\mathrm{IS}}$ ) for each locus, both over the whole population, and for each breed separately. Calculations are based on the method by Weir and Cockerham of 1984 (Weir \& Cockerham, 1984; Goudet, 2001). The analysis of molecular variance (AMOVA) and the deviation from Hardy Weinberg Disequilibrium (HWE) were conducted using ARLEQUIN version 3.5.1.2 (Excoffier and Lischer, 2010).

The analysis of the population structure was performed with the software STRUCTURE 2.3.4 (Pritchard et al., 2000; Falush et al., 2003) to determine the true number of populations (K), by using Bayesian-based assignment principles. The model used for the simulation assumes admixture in the ancestry, and therefore assumes correlated allele frequencies. The model assumed the probability of the number of populations $(\operatorname{Ln} \operatorname{Pr}(X \mid K))$ to be $2 \leq K \leq 9$. Five independent runs were performed for each $\mathrm{K}$, and the probability value for each $\mathrm{K}$ was averaged over the runs. The runs were carried out 
with a burn-in period of 100,000 steps, followed by 500,000 Markov chain Monte Carlo (MCMC) iterations.

\section{Results}

A total of 201 different alleles were detected across the 25 microsatellite markers analysed in the 240 genotyped individuals. The mean number of observed alleles across all populations was 8.0, with the lowest number being three alleles (MAF209) ranging up to twelve alleles (HSC, SRCRSP8, BM1258) over all populations (Table 1). A summary of the total number of alleles (TNA) per locus for the total population and for the separate breeds are presented in Fig. 2. The observed and expected heterozygosity per locus across the populations varied from 0.363 to 0.817 and 0.367 to 0.832 respectively. The mean estimates of the $F$-statistics found by jack-knifing over all the populations were $F_{I T}=0.083 \pm 0.013, F_{S T}=0.064 \pm 0.007$ and $F_{I S}=0.020 \pm 0.013$. The polymorphic information content (PIC) for the 25 markers applied in the study varied between 0.334 and 0.821 per locus with an average of 0.629. Results indicate that these markers were sufficiently informative to evaluate genetic variation in this relatively small population (Table1).

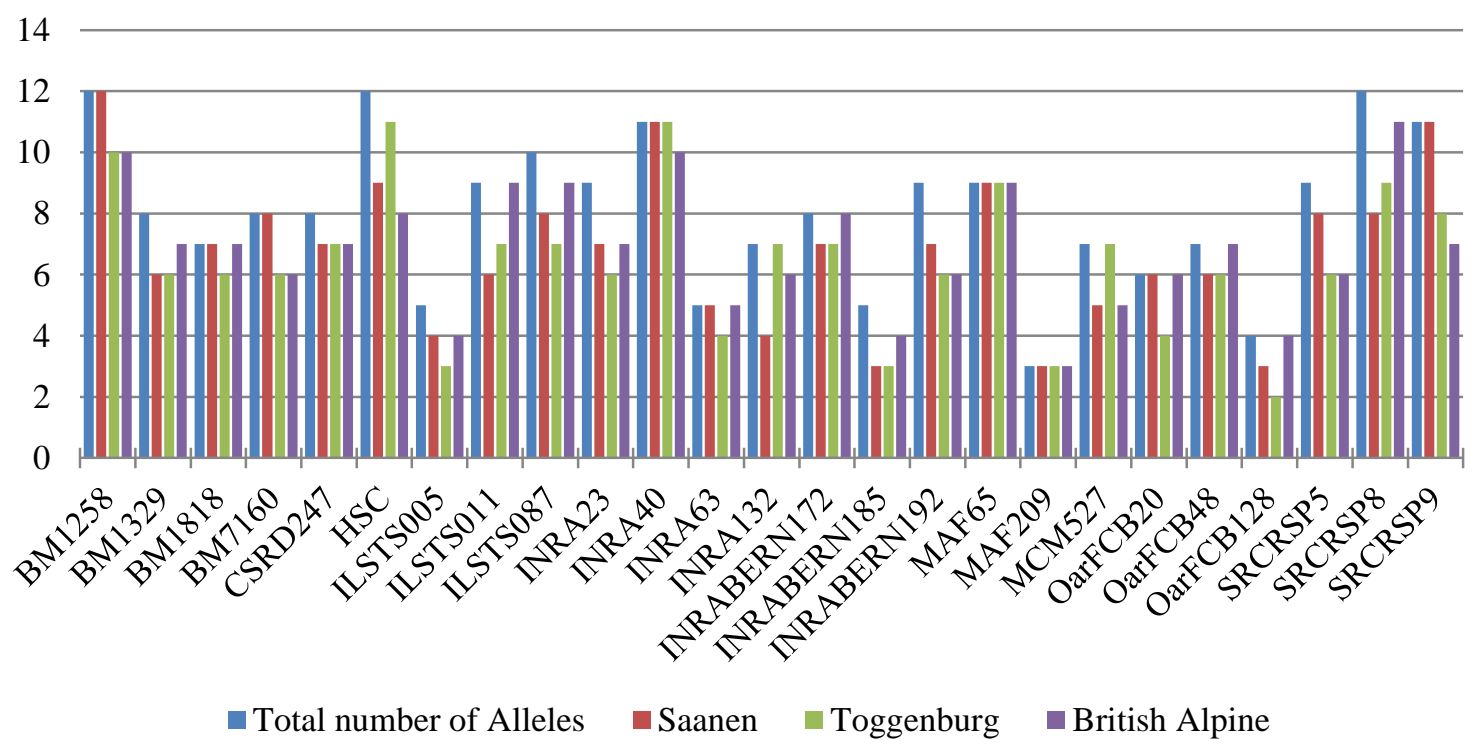

Fig. 2. Comparison of the total number of alleles (TNA) found for each of the 25 microsatellite markers in the global population as well as for each breed 
Table 1 Summary statistics across the three goat populations for the 25 microsatellite markers

\begin{tabular}{|c|c|c|c|c|c|c|c|}
\hline Locus & Number of alleles & $F_{I T}(F)$ & $F_{S T}(\theta)$ & $F_{I S}(f)$ & $\mathbf{H}_{\mathbf{E}}$ & $\mathbf{H}_{\mathbf{O}}$ & PIC \\
\hline BM1258 & 12 & 0.146 & 0.036 & 0.115 & 0.832 & 0.721 & 0.811 \\
\hline BM1329 & 7 & 0.034 & 0.058 & -0.025 & 0.677 & 0.669 & 0.628 \\
\hline BM1818 & 7 & -0.005 & 0.037 & -0.044 & 0.800 & 0.817 & 0.772 \\
\hline BM7160 & 8 & 0.156 & 0.077 & 0.086 & 0.754 & 0.657 & 0.714 \\
\hline CSRD247 & 8 & 0.004 & 0.029 & -0.026 & 0.644 & 0.649 & 0.593 \\
\hline HSC & 12 & 0.099 & 0.076 & 0.024 & 0.822 & 0.764 & 0.801 \\
\hline ILSTS005 & 5 & 0.071 & 0.097 & -0.029 & 0.466 & 0.450 & 0.396 \\
\hline ILSTS011 & 9 & -0.056 & 0.009 & -0.065 & 0.737 & 0.781 & 0.696 \\
\hline ILSTS087 & 10 & 0.113 & 0.135 & -0.026 & 0.773 & 0.725 & 0.738 \\
\hline INRA23 & 9 & 0.121 & 0.044 & 0.08 & 0.841 & 0.715 & 0.821 \\
\hline INRA40 & 11 & 0.172 & 0.065 & 0.114 & 0.674 & 0.607 & 0.618 \\
\hline INRA63 & 5 & 0.108 & 0.022 & 0.088 & 0.594 & 0.540 & 0.514 \\
\hline INRA132 & 7 & 0.097 & 0.014 & 0.084 & 0.492 & 0.441 & 0.471 \\
\hline INRABERN172 & 8 & 0.12 & 0.043 & 0.08 & 0.729 & 0.653 & 0.688 \\
\hline INRABERN185 & 5 & -0.044 & 0.022 & -0.067 & 0.445 & 0.469 & 0.396 \\
\hline INRABERN192 & 9 & 0.144 & 0.11 & 0.038 & 0.609 & 0.546 & 0.556 \\
\hline MAF65 & 9 & 0.047 & 0.069 & -0.024 & 0.367 & 0.363 & 0.334 \\
\hline MAF209 & 3 & 0.028 & 0.038 & -0.01 & 0.824 & 0.808 & 0.802 \\
\hline MCM527 & 7 & 0.082 & 0.101 & -0.021 & 0.649 & 0.621 & 0.599 \\
\hline OarFCB20 & 6 & 0.098 & 0.127 & -0.034 & 0.398 & 0.366 & 0.334 \\
\hline OarFCB48 & 7 & 0.002 & 0.045 & -0.045 & 0.684 & 0.650 & 0.643 \\
\hline OarFCB128 & 4 & 0.117 & 0.095 & 0.024 & 0.778 & 0.791 & 0.744 \\
\hline SRCRSP5 & 9 & 0.084 & 0.084 & 0 & 0.536 & 0.508 & 0.508 \\
\hline SRCRSP8 & 12 & 0.099 & 0.067 & 0.035 & 0.814 & 0.753 & 0.788 \\
\hline SRCRSP9 & 11 & 0.158 & 0.082 & 0.083 & 0.783 & 0.682 & 0.752 \\
\hline Average & 8 & $0.083 \pm 0.013$ & $0.064 \pm 0.007$ & $0.020 \pm 0.013$ & 0.669 & 0.630 & 0.629 \\
\hline
\end{tabular}

HE: expected heterozygosity; HO: observed heterozygosity; PIC: polymorphic information content 
A total of 11 markers deviated from Hardy Weinberg equilibrium (HWE) across all three populations. In the Saanen population 20 of the 25 loci were in Hardy Weinberg equilibrium $(P>$ 0.05), while in the British Alpine and the Toggenburg six loci deviated significantly from HWE in each population. One locus (INRA40) had a deviation from HWE in all three breeds, while three more loci (ILSTS011, MAF209 and OarFCB128) deviated only in the Toggenburg and British Alpine, and BM1258 deviated from HWE only in the Saanen and British Alpine.

There were 33 private alleles observed in the three populations, but only four of the 33 private alleles had a frequency greater than $1 \%$ in the Saanen and British Alpine populations (two private alleles each). The Toggenburg did not have any private alleles that occurred more frequently than in $0.5 \%$ of the population. The highest private allele frequency observed was 0.036 in the Saanen (allele 215 of INRA23).

Analyses of genetic diversity within the populations indicated a relatively high diversity in all three breeds, with unbiased heterozygosity values of up to $65 \%$ in the Saanen population (Table 2) and 64\% and 62\% in the British Alpine and Toggenburg respectively. The highest mean number of alleles $(6.84 \pm 2.08)$ was observed in the British Alpine, closely followed by the Saanen $(6.80 \pm 2.47)$ and the Toggenburg $(6.44 \pm 2.42)$.

Population differentiation indicated by $F_{S T}$ values were low positive in all three breeds as shown in Table 3. $F_{S T}$ values among the three breeds indicated a slight variation, while $\mathrm{F}_{\text {IT }}$ values varied from 0.046 for the Saanen to as low as -0.006 in the Toggenburg (Table 3). 56\% of the markers showed a negative $F_{I S}$ value in the Saanen population, while the remaining eleven had low positive values. In the Toggenburg nineteen of the 25 markers (76\%) had negative $F_{I S}$ values, while the remaining six had low positive values. The British Alpine had fewer markers with a negative $F_{I S}$ value compared to the Toggenburg. The average $F_{I S}$ values for the Toggenburg (-0.063), the British Alpine $(-0.035)$ and the Saanen (-0.005) were all low negative values indicating limited inbreeding.

The partitioning of variance was explained by the AMOVA results presented in Table 4, indicating that the largest component of the genetic variation can be ascribed to variation within populations $(91.7 \%)$, and only $6.40 \%$ and $1.87 \%$ due to differences among the populations and among individuals within the populations respectively. 
Table 2 Summary statistics estimated for the Saanen, Toggenburg and British Alpine populations genotyped with 25 microsatellites

\begin{tabular}{lllllll}
\hline Population & $\begin{array}{l}\text { Sample } \\
\text { size }\end{array}$ & $\begin{array}{l}\text { Loci } \\
\text { typed }\end{array}$ & Unbiased Hz \pm & Obs Hz \pm SD & n Alleles \pm & PIC \\
& & & & & SD & \\
\hline Saanen & 130 & 25 & $0.650 \pm 0.0300$ & $0.626 \pm$ & $6.80 \pm 2.47$ & 0.603 \\
& & & & 0.0085 & & \\
Toggenburg & 51 & 25 & $0.624 \pm 0.0388$ & $0.634 \pm$ & $6.44 \pm 2.42$ & 0.577 \\
& & & & 0.0135 & & \\
British & 59 & 25 & $0.641 \pm 0.0291$ & $0.634 \pm$ & $6.84 \pm 2.08$ & 0.596 \\
Alpine & & & & 0.0126 & & \\
\hline
\end{tabular}


Table 3 Wright's $F$-statistics for the Saanen, Toggenburg and British Alpine populations, for each of the 25 microsatellite markers ${ }^{1}$

\begin{tabular}{|c|c|c|c|c|c|c|c|c|c|}
\hline \multirow[t]{2}{*}{ Locus } & \multicolumn{3}{|c|}{ Saanen } & \multicolumn{3}{|c|}{ Toggenburg } & \multicolumn{3}{|c|}{ British Alpine } \\
\hline & $F_{I T}(F)$ & $F_{S T}(\theta)$ & $F_{I S}(f)$ & $F_{I T}(F)$ & $F_{S T}(\theta)$ & $F_{I S}(f)$ & $F_{I T}(F)$ & $F_{S T}(\theta)$ & $F_{I S}(f)$ \\
\hline BM1258 & 0.160 & 0.065 & 0.101 & 0.057 & 0.081 & -0.027 & 0.113 & 0.088 & 0.027 \\
\hline BM1329 & -0.006 & 0.018 & -0.024 & -0.015 & 0.118 & -0.152 & -0.040 & 0.136 & -0.204 \\
\hline BM1818 & 0.001 & 0.085 & -0.093 & -0.055 & 0.079 & -0.146 & -0.086 & 0.021 & -0.110 \\
\hline BM7160 & 0.101 & 0.058 & 0.045 & 0.054 & -0.020 & 0.073 & 0.108 & 0.064 & 0.047 \\
\hline CSRD247 & 0.010 & 0.018 & -0.008 & -0.042 & 0.040 & -0.085 & -0.070 & 0.031 & -0.105 \\
\hline HSC & 0.044 & 0.036 & 0.009 & 0.005 & 0.008 & -0.002 & 0.004 & -0.007 & 0.011 \\
\hline ILSTS005 & -0.019 & 0.049 & -0.071 & 0.036 & 0.009 & 0.028 & -0.073 & 0.012 & -0.086 \\
\hline ILSTS011 & -0.037 & 0.030 & -0.069 & -0.251 & 0.002 & -0.254 & 0.041 & 0.014 & 0.027 \\
\hline ILSTS087 & 0.023 & 0.071 & -0.051 & -0.001 & 0.053 & -0.057 & -0.116 & 0.022 & -0.141 \\
\hline INRA23 & 0.036 & 0.055 & -0.019 & 0.010 & 0.010 & 0.000 & 0.286 & 0.081 & 0.223 \\
\hline INRA40 & 0.224 & 0.052 & 0.182 & 0.018 & 0.061 & -0.046 & 0.002 & 0.060 & -0.062 \\
\hline INRA63 & 0.094 & 0.085 & 0.010 & 0.075 & 0.074 & 0.002 & 0.139 & 0.111 & 0.031 \\
\hline INRA132 & 0.083 & 0.001 & 0.082 & 0.202 & 0.123 & 0.090 & 0.014 & 0.040 & -0.027 \\
\hline INR & 0.131 & 0.035 & 0.100 & -0.035 & 0.052 & -0.092 & 0.090 & 0.042 & 0.050 \\
\hline $\begin{array}{l}\text { INRABERN18 } \\
5\end{array}$ & -0.051 & 0.050 & -0.106 & 036 & 0.060 & -0.102 & -0.103 & 0.064 & -0.179 \\
\hline $\begin{array}{l}\text { INRABERN19 } \\
2\end{array}$ & 0.088 & 0.071 & 0.017 & -0.061 & 0.012 & -0.075 & 0.035 & 0.034 & 0.001 \\
\hline MAF65 & -0.018 & 0.068 & -0.092 & -0.029 & 0.078 & -0.116 & 0.013 & 0.043 & -0.032 \\
\hline MAF209 & 0.046 & 0.050 & -0.005 & -0.089 & 0.101 & -0.212 & -0.049 & 0.045 & -0.098 \\
\hline MCM527 & -0.101 & 0.061 & -0.172 & 0.040 & 0.044 & -0.004 & 0.160 & 0.140 & 0.023 \\
\hline OarFCB20 & -0.028 & 0.012 & -0.040 & -0.002 & 0.027 & -0.030 & -0.056 & -0.005 & -0.051 \\
\hline OarFCB48 & 0.007 & 0.063 & -0.060 & -0.179 & 0.038 & -0.225 & -0.018 & 0.037 & -0.058 \\
\hline OarFCB128 & 0.050 & 0.028 & 0.022 & -0.050 & 0.014 & -0.065 & -0.013 & -0.012 & -0.001 \\
\hline SRCRSP5 & 0.032 & 0.013 & 0.019 & -0.067 & 0.074 & -0.152 & 0.078 & 0.146 & -0.079 \\
\hline SRCRSP8 & 0.016 & 0.055 & -0.041 & 0.142 & 0.088 & 0.060 & 0.021 & 0.069 & -0.051 \\
\hline SRCRSP9 & 0.162 & 0.094 & 0.075 & 0.022 & 0.070 & -0.052 & -0.007 & 0.065 & -0.077 \\
\hline & $0.046 \pm$ & $0.05 \pm$ & -0.005 & -0.006 & $0.053 \pm$ & -0.063 & $0.019 \pm$ & $0.052 \pm$ & -0.035 \\
\hline & 0.017 & 0.005 & \pm 0.017 & \pm 0.020 & 0.008 & \pm 0.020 & 0.017 & 0.008 & \pm 0.015 \\
\hline
\end{tabular}


Table 4 AMOVA analysis for the Saanen, Toggenburg and British Alpine populations

\begin{tabular}{lllll}
\hline Source of variation & Sum of squares & $\begin{array}{l}\text { Variance } \\
\text { components }\end{array}$ & $\begin{array}{l}\text { Percentage } \\
\text { variation }\end{array}$ & P-value \\
\hline $\begin{array}{l}\text { Among populations } \\
\text { Among individuals within } \\
\quad 174.331\end{array}$ & 0.54960 & 6.40455 & 0.001 \\
$\quad 1931.945$ & 0.16097 & 1.87586 & 0.001 \\
$\begin{array}{l}\text { Within individuals } \\
\text { Total }\end{array}$ & 1880.000 & 7.87079 & 91.71959 & 0.001 \\
\hline
\end{tabular}

Table 5 Proportion of membership of each pre-defined population in each of the six clusters inferred by the STRUCTURE software ${ }^{1}$

\begin{tabular}{lccccccc}
\hline Predefined populations & \multicolumn{3}{c}{ Inferred clusters } & & \multicolumn{2}{c}{ n } \\
\cline { 2 - 7 } & \multicolumn{1}{c}{} & $\mathbf{2}$ & $\mathbf{3}$ & $\mathbf{4}$ & $\mathbf{5}$ & $\mathbf{6}$ \\
\hline Saanen & 0.022 & 0.026 & 0.067 & $\mathbf{0 . 2 1 6}$ & $\mathbf{0 . 3 5 9}$ & $\mathbf{0 . 3 1 0}$ & 130 \\
Toggenburg & 0.046 & $\mathbf{0 . 7 2 8}$ & 0.141 & 0.048 & 0.015 & 0.021 & 51 \\
British Alpine & $\mathbf{0 . 5 9 6}$ & 0.056 & 0.262 & 0.025 & 0.031 & 0.030 & 59 \\
\end{tabular}

n: number of individuals

${ }^{1}$ Major clusters in bold 
For estimation of the population structure and level of admixture, the estimated probabilities (Ln Pr) of the number of true populations (K) were varied between 2 and 9. Based on the $\operatorname{Ln} \operatorname{Pr}(\mathrm{X} \mid \mathrm{K})$ values, $\mathrm{K}=6$ was used as the most probable inferred number of populations. The portion of membership from each population in the inferred clusters is presented in Table 5. The Saanen breed clustered into 3 distinct groups, namely clusters 4 (21.6\%), 5 (35.6\%) and $6(31.0 \%) .72 .8 \%$ of the Toggenburg goats formed a single cluster, and most of the British Alpine were observed in cluster 1 (59.6\%). Cluster 3 had individuals with membership from all three breeds.

A high level of admixture was observed between the three clusters in the Saanen population, displaying a higher level of admixture in comparison to the Toggenburg and British Alpine populations. The British Alpine and the Toggenburg clustered largely together, although the presence of a hybrid group was also observed. In Figure 3 the clusters are shown according to the proportionate membership of the goats to each of the clusters.

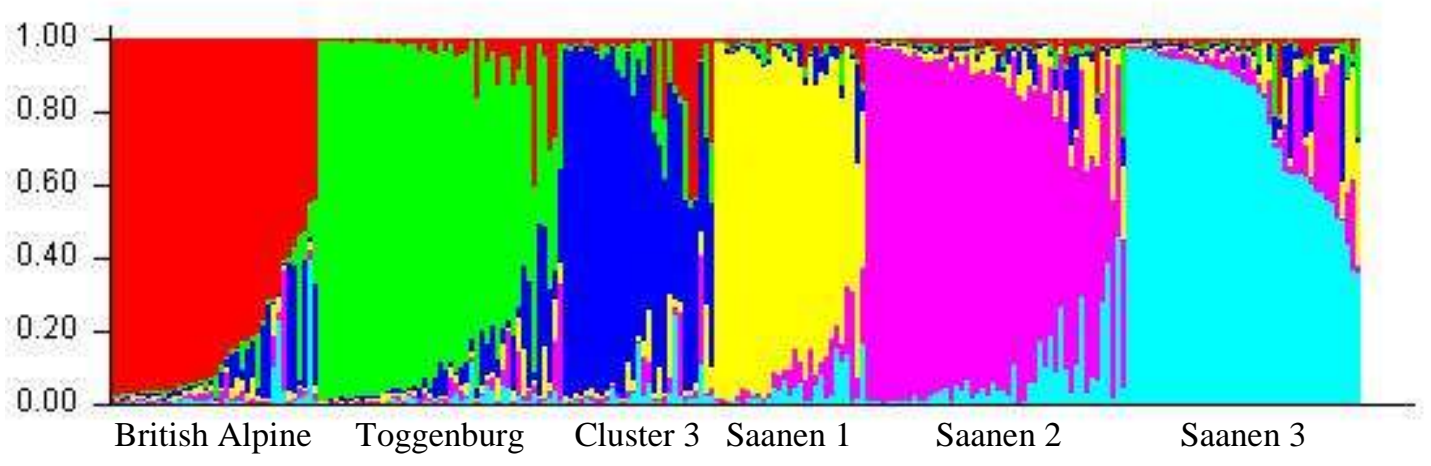

Fig. 3 A summary plot of the 240 goats arranged according to their membership to one of the six inferred populations

\section{Discussion}

For this study 25 microsatellite markers were selected to evaluate genetic diversity in South African dairy goats. 16 markers were selected from the FAO/ISAG list of recommended microsatellites for diversity studies (FAO, 2011). Due to the relative small size of the South African dairy goat populations additional markers were added that were previously confirmed to be polymorphic (Glowatzki-Mullis et al. 2008; Barrera-Saldaña et al. 2010; Bruno-de-Sousa et al. 2011; Visser et al. 2011). The average PIC across breeds was 0.50 . The average PIC value of 0.60 in the 
Saanen compared favourably with the study of Bruno-de-Sousa et al. (2011) who reported an average value of 0.67 for a panel that had 11 markers in common with this study. The mean number of alleles (MNA) across the Saanen, Toggenburg and British Alpine populations ranged from 3 to 12 (average 8), and compared well with Iamartino et al. (2005), where an MNA of 7.3 was found across nine different breeds, including the Saanen and Alpine. The majority of the markers were in HWE across the populations, with only one locus (INRA40) that deviated in all three breeds. Results indicate that the markers can be confirmed as highly informative (Tolone et al., 2012) and suitable for the analyses of genetic diversity in SA populations.

The private alleles observed in the three goat populations were low with only four alleles at a frequency higher than $1 \%$. This was low in comparison to the frequency of the private alleles identified for the Swiss Toggenburg (0.11) (Glowatzki-Mullis et al. 2008). A private allele is considered to have a high frequency if it occurs in more than $20 \%$ of the population (GlowatzkiMullis et al., 2008). From the results in this study it can be concluded that there are no private alleles that can be applied for breed identification in the South African goat populations.

The genetic diversity within the populations was high in all three breeds, with observed $\mathrm{H}_{Z}$ varying from $62.6 \%$ to $65.0 \%$. These results compared well with results (Glowatzki-Mullis et al. 2008) where Swiss Saanen (0.60) and Toggenburg (0.59) populations were studied. The differences between the observed and expected heterozygosities for the Saanen, Toggenburg and the British Alpines observed in the current study were small, indicating that the populations are largely in balance, with no significant loss of heterozygosity (Falconer, 1989).

Wright's $F$-statistics were obtained for all three breeds over all the loci, in order to determine the relationship between the breeds. Twelve of the 25 markers had negative $F_{I S}$ values, while thirteen had low positive values. The low positive average $F_{I S}$ value $(0.020)$ across populations verified the individual breeds' trends - the average $F_{I S}$ values for each separate breed were also negative, indicating limited inbreeding within the populations. Results indicated that there is low genetic differentiation within the Saanen, Toggenburg and British Alpine populations and among the three breeds as well. This is expected since the Saanen, Toggenburg and British Alpine breeds have all been developed as dairy goats, and therefore are expected to have a large number of traits in common. The 
$F_{S T}$ value (0.064) across populations is very similar to the values found for the Saanen, Toggenburg and British Alpine breeds individually (0.050, 0.053 and 0.52 respectively). These values are similar to results reported by (Tolone et al., 2012), who found that differentiation between five Sicilian sheep breeds were very slight as the breeds shared a common history and similar breeding practices. This is probably also true for the three dairy goat breeds in this study, all three originated from Swiss stock and have undergone selection for milk production traits.

These results were further confirmed when an AMOVA was performed, which indicated that most of the variation seen is due to the differences in the individuals themselves (91.7\%), while 6.4\% of the variation is due differentiation between breeds. A small amount of differentiation (1.9\%) is due to the breed effect within populations. The average $F_{\mathrm{IT}}(0.08)$ and $\mathrm{F}_{\mathrm{IS}}(0.02)$ values found in this study were in a similar range to values for five Sicilian sheep breeds (0.08 and 0.03) (Tolone et al., 2012) and Swiss goat populations ( $\mathrm{F}_{\mathrm{IS}}$ of 0.014) (Glowatzki-Mullis et al., 2008).

Population structure revealed three populations of Saanen, Toggenburg and British Alpine. The Saanen population further subdivided into three distinct groups, indicating that some genetic differentiation within the Saanen breed is taking place (Glowatzki-Mullis et al., 2008; Bruno-deSousa et al., 2011). Although several different herds from various geographical locations were sampled, no clear geographical influence was seen that could explain this clustering pattern. Two of the main contributors to Saanen cluster 2 are from the Western Cape and Limpopo respectively, which are at opposite ends of the country. Saanen cluster 1 consisted of goats mainly from the Western Cape and Gauteng, while Saanen cluster 3 included goats from Limpopo, KwaZulu Natal and the Western Cape. However, when the breeders' practice of breeding their own replacement bucks is taken into account (Muller, 2005), it becomes probable that their genetic material originated from a common ancestor. Due to mostly breeding their own replacement bucks, the genetic influence of the ancestral goats would become amplified in these herds, resulting in some line breeding which in turn caused these populations to differentiate to the point that they formed their own clusters.

An unexpected differentiated population was found in an additional cluster, where individuals with membership from all three breeds were present, consisting primarily of British Alpine and Toggenburg individuals, with a smaller number of Saanen individuals. The goats in this cluster 
originated from several different provinces and farms. Admixture between the goats found in the additional cluster indicate that they have differentiated from their parent Saanen, Toggenburg and British Alpine populations and this cluster could therefore be considered as a hybrid or crossbred population. Glowatzki-Mullis et al. (2008) observed a similar situation where the Tessin Grey goat, Nera Verzasca goat and the Peacock goat breeds grouped together in the same cluster due to similar geographical origin and breed history that resulted in admixture causing these populations to be genetically more similar. It is interesting to note that at least one of the goats found in this cluster was registered as a purebred animal, but does not cluster with its own breed cluster. As the South African Milch Goat Breeders' Society allows the registration of goats with unknown parents based on a physical inspection, it is conceivable that such a crossbred animal may be inadvertently assimilated into one of the herd books.

Although official pedigree recording for dairy goat breeds were established in a similar time period as for dairy cattle breeds in South Africa (early to mid-1900's) (Van Marle-Köster et al., 2013) only a small number of registered dairy goat farmers participate in milk recording and most of the goats in the South African population have not been subjected to intense selection practices. Results from a population structure analyses in registered dairy goats in South Africa found that the pedigree completeness vary between the breeds $(71 \%, 73 \%$ and $83 \%$ for the Saanen, Toggenburg and British Alpine respectively) and inbreeding estimates ranged from $4.51 \%$ for the British Alpine to $8.57 \%$ for the Toggenburg (Bosman et al., 2014). These estimates based on the pedigree data available was higher compared to the results obtained from the molecular data. This highlights the limitations of incomplete pedigrees for smaller populations and indicates the necessity of using genetic data for management of these populations.

Based on the DNA marker analyses that included both registered and commercial dairy goats the genetic diversity in the South African population is sufficient and inbreeding is low. There is clearly some admixture among the commercial populations especially in small herds where more than one breed is kept and only one buck of a breed is available. Therefore breeders should be aware of uncontrolled cross breeding among the populations. The ability of the populations to respond to selection pressure and increase productivity is subjected to the amount of genetic diversity found 
within breeds (Boettcher, 2001). This will be an important aspect for future selection of dairy goats in South Africa. As the demand for dairy goat products increase and the industry expands it is expected that more emphasis will be placed on traits of economic importance in selection programs. In a relatively small dairy goat population such as in South Africa, it will be important to monitor and maintain genetic diversity using both molecular and quantitative breeding tools.

Currently the South African Milch Goat Breeders' Society (SAMGBS) allows the registration of goats with unknown parents with the relevant herdbook based on an inspection. Coat colour is however not an accurate indication of an animal's true breed. It is instead recommended that goats with unknown parents rather be added to an appendix herdbook to prevent the dilution of data in the Herdbook Proper. It should be ensured that animals added to the Herdbook Proper share at least 75\% of their genetic make-up with other animals in the herdbook.

\section{Conclusion}

This study was the first attempt to characterise the South African dairy goat population on a molecular level. A population structure analysis indicated that the Saanen differentiated into three sub-populations, while the Toggenburg and the British Alpine each segregated into their own clusters. A crossbred population cluster was also identified, in which mainly Toggenburg and British Alpine goats were found. It was concluded that there is sufficient variation in the South African populations to withstand selection pressure, but that caution should be exercised when goats with unknown parents are added to the purebred herd books. It is recommended that the evaluation of the Saanen, Toggenburg and British Alpine breeds should be repeated every ten years to monitor the change in the genetic diversity of these breeds, to enable corrective measures to be implemented timeously should the genetic diversity decrease.

\section{Acknowledgement/Conflict of interest}

The authors acknowledge that there has been no conflict of interest during the course of this study. This work is based on the research supported in part by a number of grants from the National Research Foundation of South Africa (UID: 78566 (NRF RISP grant for the ABI3500)). The Grant 
holders acknowledge that opinions, findings and conclusions or recommendations expressed in any publication generated by the NRF supported research are that of the authors and that the NRF accepts no liability whatsoever in this regard.

\section{References}

Barrera-Saldaña, H.A., Ascacio-Martínez, J.A., Sifuentes-Rincón, A.M., Arellano-Vera, W., Arbiza, S.I., 2010. Applications of biotechnology and genomics in goats. Small Ruminant Res. 89, 81-90.

Boettcher, P.J., 2001. 2020 Vision? The future of dairy cattle breeding from an academic perspective. J. Dairy Sci. 84, Supplement, E62-E68.

Bosman, L., Van Marle-Köster, E., Visser, C., 2014. Population structure of South African commercial dairy goats. European Regional Conference on Goats 2014, Debrecen, Hungary and Oradea, Romania, 7-13 April 2014, p. 48.

Bruno-de-Sousa, C., Martinez, A.M., Ginja, C., Santos-Silva, F., Carolino, M.I., Delgado, J.V., Gama, L.T., 2011. Genetic diversity and population structure in Portuguese goat breeds. Livest. Sci. 135, 131-139.

Directorate: Animal Production, 2007. Status of the South African goat industry. In: Department of Agriculture, S.A., Com Mark Trust \& National Agricultural Marketing Council (Ed.). Department of Agriculture, Pretoria, South Africa.

Excoffier, L., Lischer, H.E.L., 2010. Arlequin suite ver 3.5: A new series of programs to perform population genetics analyses under Linux and Windows. Molecular Ecology Resources 10, 564-567.

Falconer, D.S., 1989. Introduction to quantitative genetics, Longman Scientific \& Technical, Essex, England.

Falush, D., Stephens, M., Pritchard, J.K., 2003. Inference of population structure: Extensions to linked loci and correlated allele frequencies. Genetics 164, 1567-1587.

FAO, 2011. Molecular genetic characterization of animal genetic resources, Rome.

FAO, 2012. FAOSTAT. FAO.

Glaubitz, J.C., 2004. CONVERT: A user-friendly program to reformat diploid genotypic data for commonly used population genetic software packages. Mol. Ecol. Notes 4, 309-310. 
Glowatzki-Mullis, M.-L., Muntwyler, J., Baumle, E., Gaillard, C., 2008. Genetic diversity measures of Swiss goat breeds as decision-making support for conservation policy. Small Ruminant Res. 74, 202-211.

Goudet, J., 2001. FSTAT, a program to estimate and test gene diversities and fixation indices (version 2.9.3). Available from http://www.unil.ch/izea/softwares/fstat.html. Updated from Goudet (1995). Iamartino, D., Bruzzone, A., Lanza, A., Blasi, M. \& Pilla, F., 2005. Genetic diversity of Southern Italian goat populations assessed by microsatellite markers. Small Ruminant Res. 57, 249-255.

Muller, C.J.C., 2005. Genetic parameter estimation and breeding plans for the South African dairy goat herd. Department of Animal Sciences,, Faculty of Agricultural and Forestry Sciences. University of Stellenbosch, Stellenbosch.

Park, S.D.E., 2001. Trypanotolerance in West African cattle and the population genetic effects of selection [ Ph.D. thesis ] University of Dublin.

Pritchard, J.K., Stephens, M., Donnelly, P., 2000. Inference of population structure using multilocus genotye data. Genetics 155, 945-959.

Saitbekova, N., Gaillard, C., Obexer-Ruff, G., Dolf, G., 1999. Genetic diversity in Swiss goat breeds based on microsatellite analysis. Anim. Genet. 30, 36-41.

Tolone, M., Mastrangelo, S., Rosa, A.J.M., Portolano, B., 2012. Genetic diversity and population structure of Sicilian sheep breeds using microsatellite markers. Small Ruminant Res. 102, 18-25.

Van Marle-Köster, E., Visser, C., Berry, D.P., 2013. A review of genomic selection - Implications for the South African beef and dairy cattle industries. S. Afr. J. Anim. Sci. 43, 1-17.

Visser, C., Van Marle-Köster, E., Friedrich, H., 2011. Parentage verification of South African Angora goats, using microsatellites markers. S. Afr. J. Anim. Sci. 41, 250-255.

Weir, B.S. \& Cockerham, C.C., 1984. Estimating $F$-statistics for the analysis of population structure. Evolution. 38, 1358-1370. 